\title{
Study of Ionospheric Variability Using GNSS Observations
}

\author{
Jouan Taoufiq1, Bouziani Mourad1, Azzouzi Rachid1, Christine Amory-Mazaudier ${ }^{2,3}$ \\ ${ }^{1}$ Institute of Agronomy and Veterinary Medicine, Rabat, Morocco \\ ${ }^{2}$ Université Pierre et Marie Curie (UPMC), Paris, France \\ ${ }^{3}$ T/ICT4D Abdus Salam ICTP, Trieste, Italy \\ Email: taoufiqjouan@gmail.com,m.bouziani@iav.ac.ma,bouzianim@gmail.com,r.azzouzi@iav.ac.ma, \\ christine.a mory@lpp.polytechnique.fr
}

How to cite this paper: Taoufiq, J., Mourad, B., Rachid, A. and Amory-Mazaudier, C. (2018) Study of Ionospheric Variability Using GNSS Observations. Positioning, 9, 79-96.

https://doi.org/10.4236/pos.2018.94006

Received: October 29, 2018

Accepted: November 27, 2018

Published: November 30, 2018

Copyright (c) 2018 by authors and Scientific Research Publishing Inc. This work is licensed under the Creative Commons Attribution International License (CC BY 4.0).

http://creativecommons.org/licenses/by/4.0/

\begin{abstract}
With the increasing number of applications of Global navigation satellite system, the modeling of the ionosphere is a crucial element for precise positioning. Indeed, the ionosphere delays the electromagnetic waves which pass through it and induces a delay of propagation related to the electronic density (TEC) Total Electronic Content and to the frequency of the wave. The impact of this ionospheric error often results in a poor determination of the station's position, particularly in strong solar activity. The first part of this paper focuses on a bibliographic study oriented first of all on the study of the ionosphere in relation to solar activity and secondly on the determination of the total electron content using GNSS measurements from the IGS network reference stations. Measurements were made on two permanent stations "RABT", "TETN". We selected years of GNSS measurements to evaluate the geomagnetic impact on the ionosphere, 2001, 2009 and 2013. A description of the ionospheric disturbances and geomagnetic storms was analyzed by determination of TEC, especially in high solar activity. The results show a strong dependence of the ionospheric activity with the geomagnetic activity.
\end{abstract}

\section{Keywords}

GNSS, TEC, IGS

\section{Introduction}

Ionosphere is a reflective and refractive medium for electromagnetic waves. It is important to monitor and model the ionosphere since it affects communication systems, space based navigation systems and space weather, among others. Using geometry-free linear combination of code and phase observables from dual 
frequency GPS receivers, we can extract the total electron content (TEC) along the ray-path from the satellite to the receiver [1]. The integral of the number of electrons along the ray-path is usually called Slant Total Electron Content (STEC) and measured in units of TEC Units (TECU: 1TECU $=1016$ electrons $/ \mathrm{m}^{2}$ ). STEC is a quantity which is dependent on the ray path geometry through the ionosphere. The user can easily obtain the absolute TEC by using mapping function. The single layer thin-shell model was employed to compute the absolute vertical TEC (VTEC). Diurnal and seasonal variations were analyzed with TEC data derived from GNSS dual-frequency observations along with the solar activity dependence of TEC at the RABT and TETN stations. Data interpolated with information from IGS Global Ionosphere Maps (GIMs) were also used in the analysis [2]. TEC data from GIMs and GNSS observations are used to illustrate the variation of VTEC at the RABT $\left(33.99^{\circ} \mathrm{N}, 6.85^{\circ} \mathrm{W}\right)$ and TETN $\left(35.56^{\circ} \mathrm{N}, 5.36^{\circ} \mathrm{W}\right)$ station. The comparison with VTEC of GIMs map and GNSS observation has validated our results and demonstrates strong correlation between these two models.

In this paper, estimation of ionospheric effect from dual frequency measurements is discussed. In Section 2, equations of observations of dual frequency are described briefly. This study contains a description of diurnal and seasonal variations of TEC, and the influence of geomagnetic activity on the VTEC values, especially during the low and high solar activity period 2001, 2009.

\section{Methodology}

\subsection{Dual-Frequency Model of Ionosphere}

The use of two-frequency GNSS stations allow to calculate the STEC (Slant Tec) which is the integral of the electronic density along the path of the signal between satellite and receiver.

There are three techniques for measuring total electronic content (TEC): ionospheric soundings, radar and GNSS. There are two main approaches: Smith's 1987 single-frequency method [3] and Warrant's 1996 dual-frequency method [4]. In this article, we used the two-frequency method using two GPS signals of frequencies $f_{1}$ and $f_{2}$. The two-frequency method is the most efficient to determinate the TEC. GPS satellites currently transmit two signals in the L-band called $L_{1}$ and $L_{2}$ radio frequencies $f_{1}=1575.42 \mathrm{Mhz}$ and $f_{1}=1227.60$ Mhz and wavelength $\lambda_{1}=19 \mathrm{~cm}$ and $\lambda_{2}=24.4 \mathrm{~cm}$ respectively.

\subsection{Code and Carrier Phase Observation Equation}

The two-frequency method is based on the "geometry free" combination named $L_{4}$. This combination eliminates all terms relating to geometry (distances) and clocks. However, it depends mainly on ionospheric refraction and differential phase delays [4].

The general form of the pseudo-distance and carrier phase observation equations are: 


$$
\begin{aligned}
P_{r, f_{i}}^{s}= & \rho_{r}^{s}+c * d t_{r e c}-c * d t^{s a t}-c * \Delta t e^{s a t}+d_{f_{i}}^{s}+d_{r, f_{i}}+T_{r, f_{i}}^{s}+I_{r, f_{i}}^{s} \\
& +\Delta R_{r}^{s}+m_{r}^{s}+e_{P, r}^{s} \\
L_{r, f_{i}}^{s}= & \rho_{r}^{s}-\lambda * N_{r}^{s}+c * d t_{r e c}+b_{r, f_{i}}-\lambda * \phi_{r}\left(t_{0}\right)-c * d t^{s a t}-c * \Delta t^{s a t} \\
& +b_{f i}^{s}+\lambda * \phi^{s}\left(t_{0}\right)+T_{r, f_{i}}^{s}-I_{r, f_{i}}^{s}+\Delta R_{r}^{s}+\mu_{r}^{s}+d p_{u}^{s}+\varepsilon_{P, r}^{s}
\end{aligned}
$$

The geometric distance is expressed by:

$$
\begin{aligned}
& \multicolumn{1}{c}{\rho_{r}^{s}=\sqrt{\left(X_{s}-X_{r}\right)^{2}+\left(Y_{s}-Y_{r}\right)^{2}+\left(Z_{s}-Z_{r}\right)^{2}}} \\
& \rho_{r}^{s}: \text { The geometric distance between the satellite and the receiver } \\
& 00 d t_{r e c}: \text { Clock error of the receive } \\
& d^{s a t}: \text { Clock error of the satellite } \\
& \Delta t^{s a t}: \text { Relativistic time correction associated with the satellite } \\
& d_{f_{i}}^{s}: \text { Instrumental code delay of the satellite for code measurement } \\
& d_{r, f_{i}}: \text { Instrumental code delay of the receiver for code measurement } \\
& b_{f_{i}}^{s}: \text { Instrumental code delay of the satellite for phase measurement } \\
& b_{r, f_{i}}: \text { Instrumental code delay of the receiver for phase measurement } \\
& T_{r, f_{i}}^{s}: \text { Tropospheric delay to the frequency } f_{i} \\
& I_{r, f_{i}}^{s}: \text { Ionospheric delay to the frequency } f_{i} \\
& N_{r}^{s}: \text { Ambiguity between the receiver path and the satellite } \\
& \phi_{r}\left(t_{0}\right) \quad: \text { Originally phase for the receiver } \\
& \phi^{s}\left(t_{0}\right) \quad: \text { Originally phase for the satellite } \\
& \Delta R_{r}^{s} \quad: \text { Relativistic correction associated with distance } \\
& m_{r}^{s} \quad: \text { Multipath effect for code measurement } \\
& \mu_{r}^{s} \quad: \text { Multipath effect for phase measurement } \\
& d_{r_{r}}^{s} \quad: \text { Correction variation of the phase center } \\
& e_{r, r}^{s} \quad: \text { Code measurement noise } \\
& \varepsilon_{P_{, r}}^{s} \quad: \text { Phase measurement noise }
\end{aligned}
$$

The ambiguity of the cycle $N_{r}^{S}$ is related to lack of knowledge of the number of the whole cycles traveled by the phase on each of the frequencies at the first moment when the signal of the satellite is received by the receiver.

The code measurement is noisy. The method of phase smoothing of the code allows to separate the measurement noise from the signal and to have a significant precision in the ionospheric delay measurement [5] [6] [7]. This method is not developed as part of this article. We used observations of the code to calculate the TEC. By using the equation for the code pseudo range for two different frequencies $f_{1}$ and $f_{2}$, it can be written as follows:

$$
P_{r, f_{1}}^{s}-P_{r, f_{2}}^{s}=I_{r, f_{1}}^{s}-I_{r, f_{2}}^{s}+\left(d_{f_{1}}^{s}-d_{f_{2}}^{s}\right)+\left(d_{r, f_{1}}-d_{r, f_{2}}\right)
$$

Equation (3) expresses the dual-frequency ionospheric model according to 
satellite and receiver-related instrumental biases,

$$
D C B^{s}=\frac{1}{c} *\left(d_{f_{1}}^{s}-d_{f_{2}}^{s}\right) \text { et } D C B_{r}=\frac{1}{c} *\left(d_{r, f_{1}}-d_{r, f_{2}}\right)
$$

Satellite bias is published daily by the international organizations of Centers of Analysis which deal with positioning: Center for Orbit Determination in Europe (CODE), by the University of Bern (Switzerland); the Jet Propulsion Laboratory (JPL) and the Crustal Dynamics Data Information System (CDDIS) in the USA, the European Space Agency (ESA) in Germany and the Technical University of Catalonia (UPC) in Spain. The values are published under the acronym "DCB" for "Differential Code Biases". We decided to retain the one calculated by CODE. However, receiver DCBs is generally unknown and should be estimated within ionosphere modeling process. Replacing the ionospheric term with the equation:

$$
\begin{gathered}
I_{r}^{s}(f)=\frac{40.3}{f^{2}} \text { STEC } \\
P 1-P 2=40.3\left(\frac{1}{f_{1}^{2}}-\frac{1}{f_{2}^{2}}\right) * S T E C+c *\left(D C B^{s}+D C B_{r}\right)
\end{gathered}
$$

Schaer found that in practice the SLM mapping function is mainly the most used [8]. In the single-layer model, it is assumed that all the electrons of the ionosphere are contained in a shell of infinitesimal thickness. The height of this layer located approximately at an altitude between 350 and $450 \mathrm{~km}$ where the electronic density is maximum. In fact, this hypothesis is only an approximation of the real physical truth since the ionosphere is situated approximately at an altitude of $50 \mathrm{~km}$ to $1000 \mathrm{~km}$ above the surface of the Earth.

The intersection between the line of sight of the satellite and this spherical shell is called the ionospheric point (Ionospheric Point IP). The projection of the ionospheric point on the surface of the Earth is called the subionospheric point (Sub-ionospheric point SIP). In Figure 1 , Zand $Z^{I}$ respectively represent the zenith angles of the GPS satellite as viewed by the receiver at a given site and at the ionospheric point. R symbolizes the terrestrial ray.

Since the satellite is not upright, the total electronic content measured along this line of sight is returned to the vertical via the projection function $\left(\frac{1}{\cos \left(Z^{I}\right)}\right)$ also named mapping function [10]. Then, we model the total vertical electron content VTEC Using the law of secant:

$$
S T E C=\frac{V T E C}{\cos Z^{I}} \quad \text { et } \sin Z^{I}=\frac{R}{R+H_{\text {iono }}} \sin Z
$$

According to Equation (5), we derive the expression of the vertical VTEC such that:

$$
V T E C=S T E C * \sqrt{1-\left(\frac{R}{R+H_{\text {iono }}} \sin Z\right)^{2}}
$$




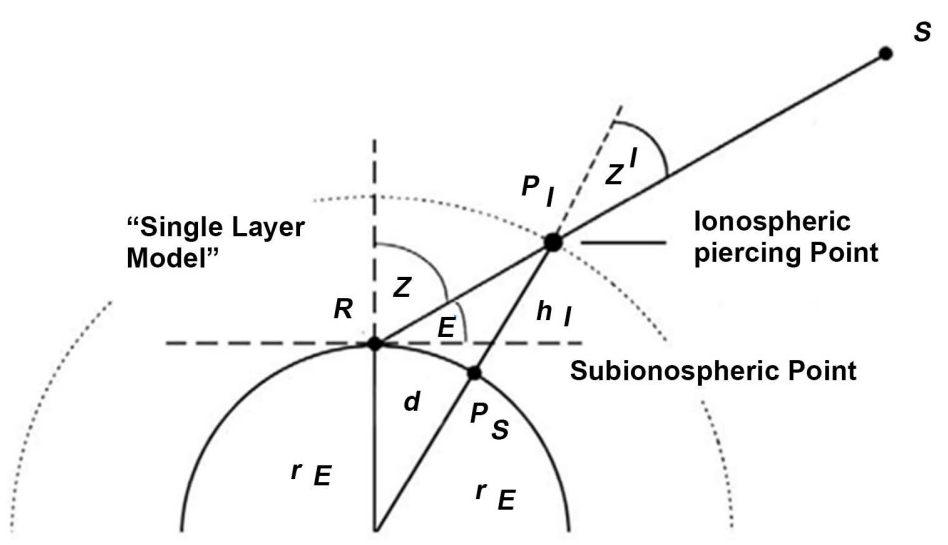

Figure 1. Single layer model of the ionosphere [9].

The zenith angle $Z$ can be calculated in case we know the coordinates of the observation site and the position of the observed satellite. $R$ is the average half-diameter of the Earth, $H_{\text {iono }}$ is the average height of the ionosphere above the Earth. The usual value of $H_{\text {iono }}$ is between $300 \mathrm{~km}$ and $400 \mathrm{~km}$. [11], reported that Hionovaries between 300 and $450 \mathrm{~km}$. Most of the research is limited to a height between 300 and $400 \mathrm{~km}$. These values correspond approximately to the altitude of the region $\mathrm{F}$ in the ionosphere. In our study we chose a height of $400 \mathrm{~km}$.

Expression of ionospheric delay is given by the following formula:

$$
\Delta_{\text {iono }}=\mp \frac{40.3}{f^{2}} S T E C=\mp \frac{40.3}{f^{2}} V T E C \times\left(\sqrt{1-\left(\frac{R}{R+H_{\text {iono }}} \sin Z\right)^{2}}\right)^{-1}
$$

$\sin Z=\cos E$ with $E$ is the satellite elevation. Hence the relationship:

$$
\Delta_{\text {iono }}=\mp \frac{40.3}{f^{2}} S T E C=\mp \frac{40.3}{f^{2}} V T E C \times\left(\sqrt{1-\left(\frac{R}{R+H_{\text {iono }}} \cos E\right)^{2}}\right)^{-1}
$$

In the following we note $\Delta_{\text {iono }}$ by $I_{\text {iono }}$.

\section{GNSS Data Processing}

The first implemented function used for the TEC determination is the read_rinex_file function. It implements the algorithm used to extract information from the RINEX file (time, Prn, L1, L2, P1, P2, C1, S1, S2) and the almanacs file (YUMA.TXT), which contains measurements of the satellite position at a specific moment.

The RINEX file format is standard, but there may be changes from one receiver to another, the way optional fields may or not appear, or there may be changes in the position of certain items in the file of ASCII format.

Elevation and azimuth calculations, required to calculate the VTEC value, are computed by the matlabelevation_azimuth function. This function has an input as matrix which contains position of satellite in the Earth Centered Earth Fixed 
(ECEF) coordinates, the satellite identification number and the time in GPS format. The algorithm for calculating the TEC is given in Figure 2. Calculation of the TEC from measurements of a station goes through the following steps:

1) RINEX format file: the RINEX (Receiver Independent Exchange) file contains the observations that make it possible to determine the local TEC or experimental TEC denoted TEC GNSS. This data are downloads from the IGS website.

2) IONEX format file: the IONEX file (Ionosphere Exchange) contains the observations of the global TEC or theoretical TEC, denoted TEC GIM. This data are downloads from the website: ftp.unibe.ch [12].

3) Almanac file (yuma file): the almanac is the set of parameters allowing a priori the state, trajectory and clock bias of one or more satellites. Each almanac is linked to a GPS week number. It is valid for all GPS stations. It is retrieved from the website https://celestrak.com/GPS/almanac/Yuma/.

4) DCB file (Differential Code Biased): it gives all the satellite and receivers bias. It is valid for one month and for all GNSS stations, and is retrieved from the website: ftp.unibe.ch.

Above is an algorithmic diagram that illustrates methodology for computation of ionospheric delay:

The process of extracting data from the RINEX file by using Matlab programming language. The program will analyze and extract the information needed to calculate the TEC. Figure 3 shows the main steps of extractions of raw data such as: observation Rinex file, ephemeris file, DCB file and Ionex file.

\section{Results and Discussions}

We calculated the monthly daily variation of the TEC of all data obtained during the days of the year. The months of a year are divided into four seasons: the

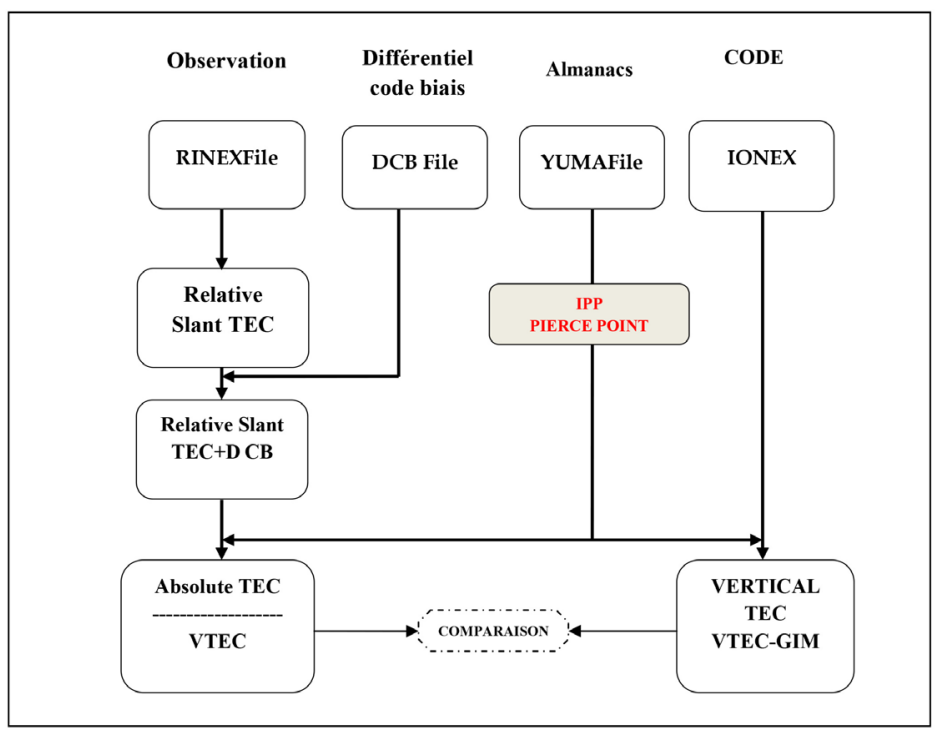

Figure 2. TEC algorithm calculation. Source: Telecom Bretagne institute. 


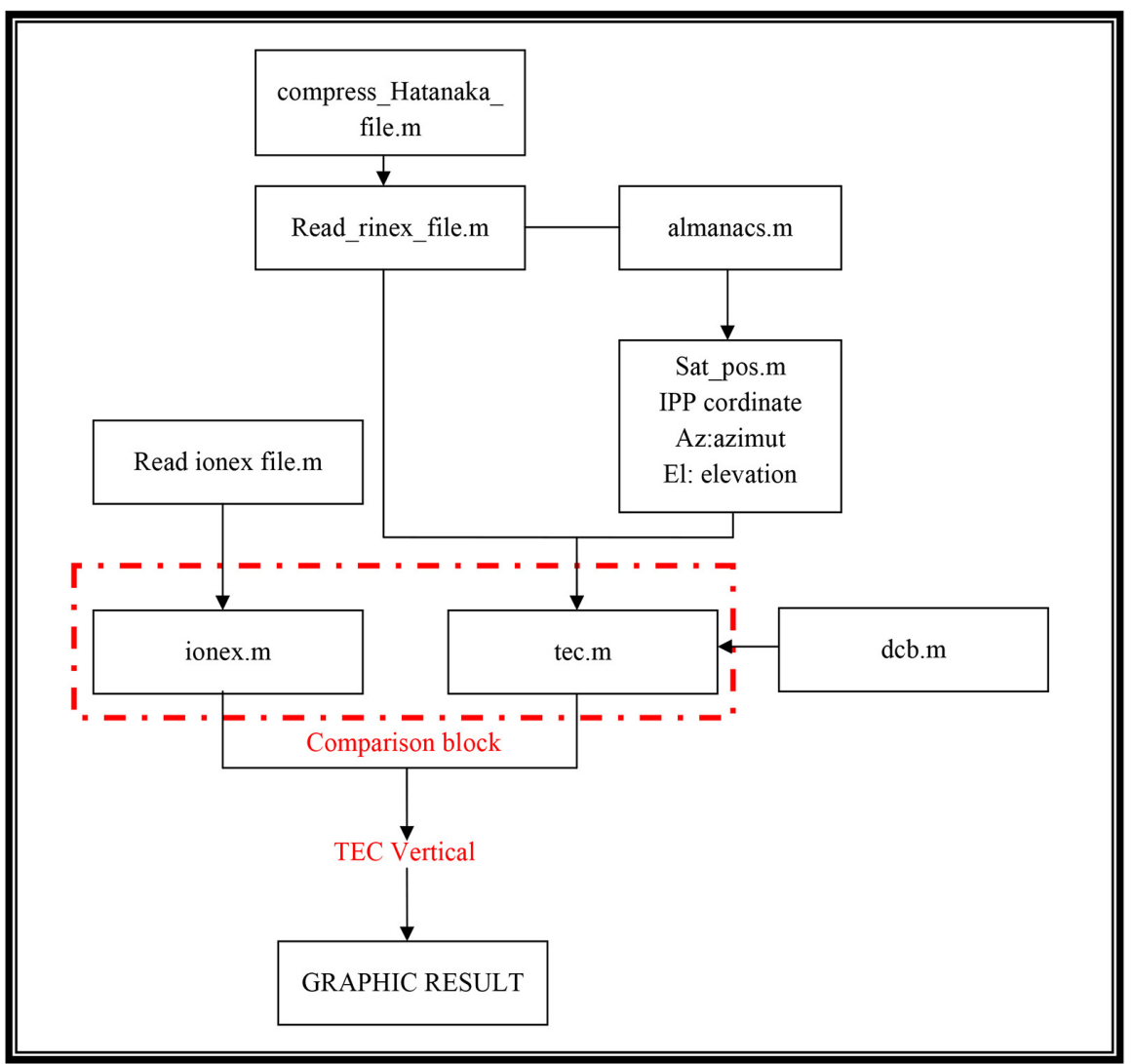

Figure 3. Subroutine Matlab for computing the vertical TEC.

equinox (March, April, September and October), winter (November, December, January and February) and summer (May, June, July and August). An analysis of the results obtained from the two permanent stations of the IGS network was evaluated in relation to the geomagnetic activity through the magnetic index Ap. The magnetic index Ap (daily measurement of the disturbance force in the Earth's magnetic field) is extracted from the data of the website: http://isgi.unistra.fr/data_plot.php.

In Figure 4, we present values of the daily magnetic index Ap for the years 2001, 2009 and 2013, on the absciss axis are represented the day of the year and on the ordinates are represented the values of the index Ap. The AP index values greater than 25 correspond to magnetically disturbed days.

In order to interpret the geomagnetic effects in relation to the ionospheric activity, we began to study the behavior of the TEC according to the days classified in ascending order of geomagnetic activity (Table 1).

\subsection{Data Description}

For the numerical analysis, the GPS observations from two stations, were selected, RABT (lat: $33^{\circ} 59^{\prime \prime} 53.16 " \mathrm{~N} /$ long: $6^{\circ} 51^{\prime 1} 15.12^{\prime \prime}$ ) and TETN (lat: $35^{\circ} 33^{\prime \prime} 43.20^{\prime \prime N} /$ long: $\left.5^{\circ} 21^{\prime \prime} 46.80 \mathrm{~W}\right)$. The GPS receivers collect the data with a 30 -second sampling rate (Figure 5). 


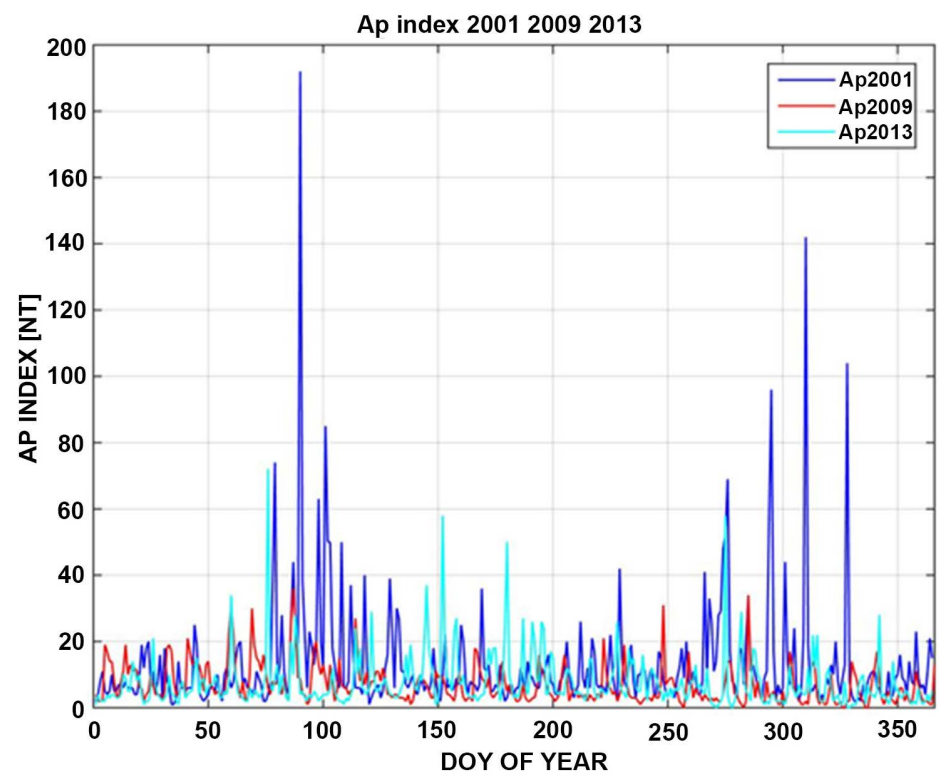

Figure 4. Magnetic index AP of the year 2001, 2009 and 2013.

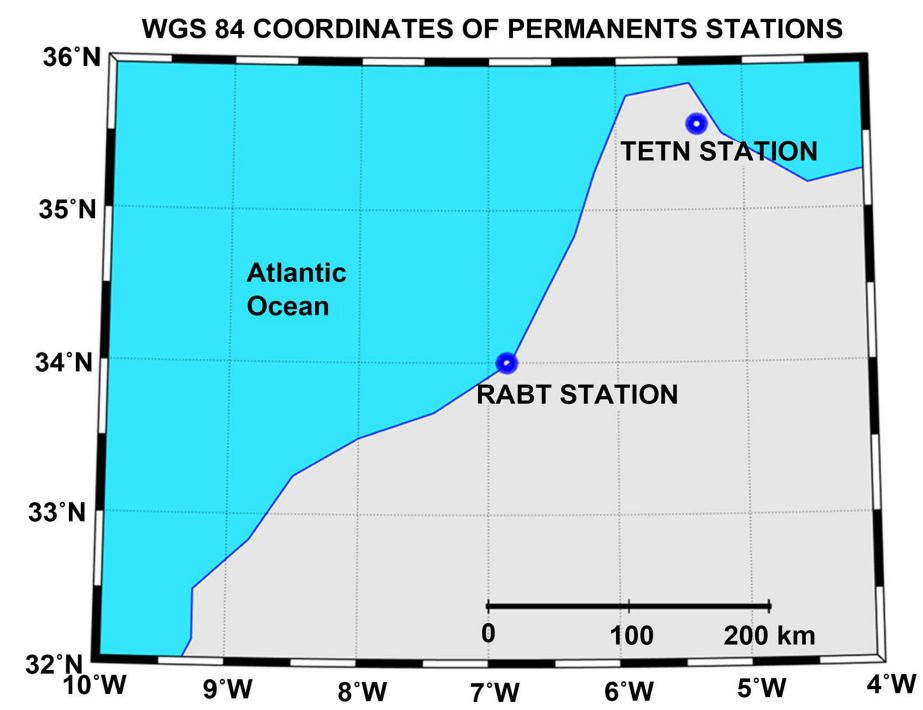

Figure 5. Locations of reference stations.

Table 1. Classification of geomagnetic activity according to the days of the year 2001-2009-2013.

\begin{tabular}{cccc}
\hline DOY & YEAR & AP VALUES & GEOMAGNETIC ACTIVITY \\
\hline $90-2001$ & 2001 & 192 & High \\
$310-2001$ & 2001 & 142 & High \\
$328-2001$ & 2001 & 104 & High \\
$17-2013$ & 2013 & 14 & Average \\
$121-2013$ & 2013 & 26 & Average \\
$315-2013$ & 2013 & 22 & Average \\
$270-2009$ & 2009 & 2 & Low \\
$257-2009$ & 2009 & 0 & Low \\
$93-2009$ & 2009 & 1 & Low \\
\hline
\end{tabular}




\subsection{Monthly Variation of the Ionosphere}

The diurnal variation of the TEC is attributed to daily rotation of the Earth. In order to determine the diurnal variation of the ionosphere, we calculated the TEC on the three specific years 2001-2009-2013. The results of a year with low solar activity year (2009) are presented in Figure 7, Figure 10, and Figure 11. Similarly for a year with a high solar activity (2001/2013) are represented in Figure 6, Figure 8, Figure 9 and Figure 11. The results are expressed in ordinate for VTEC (tecu) between 0 and 100 tecu and in abscisshour UT between 00 and 24. The blue curve represents the median VTEC values of the GNSS model and the red curve shows the median VTEC values of the GIM model. Later we will note VTEC-GIM for the GIM model and VTEC-GNSS for GNSS model.

Over the three years, the values of VTEC-GIM are in perfect agreement with those of VTEC-GNSS in all years studied. Both methods are on dual-frequency GPS observations. However, the TEC-GIM data was relatively smooth, whereas the TEC-GNSS values varied much faster in a short time. These results can be attributed to the different models used: the TEC-GNSS derived from a regional station (RABT/TETN), while the TEC-GIM was obtained from several global IGS stations.
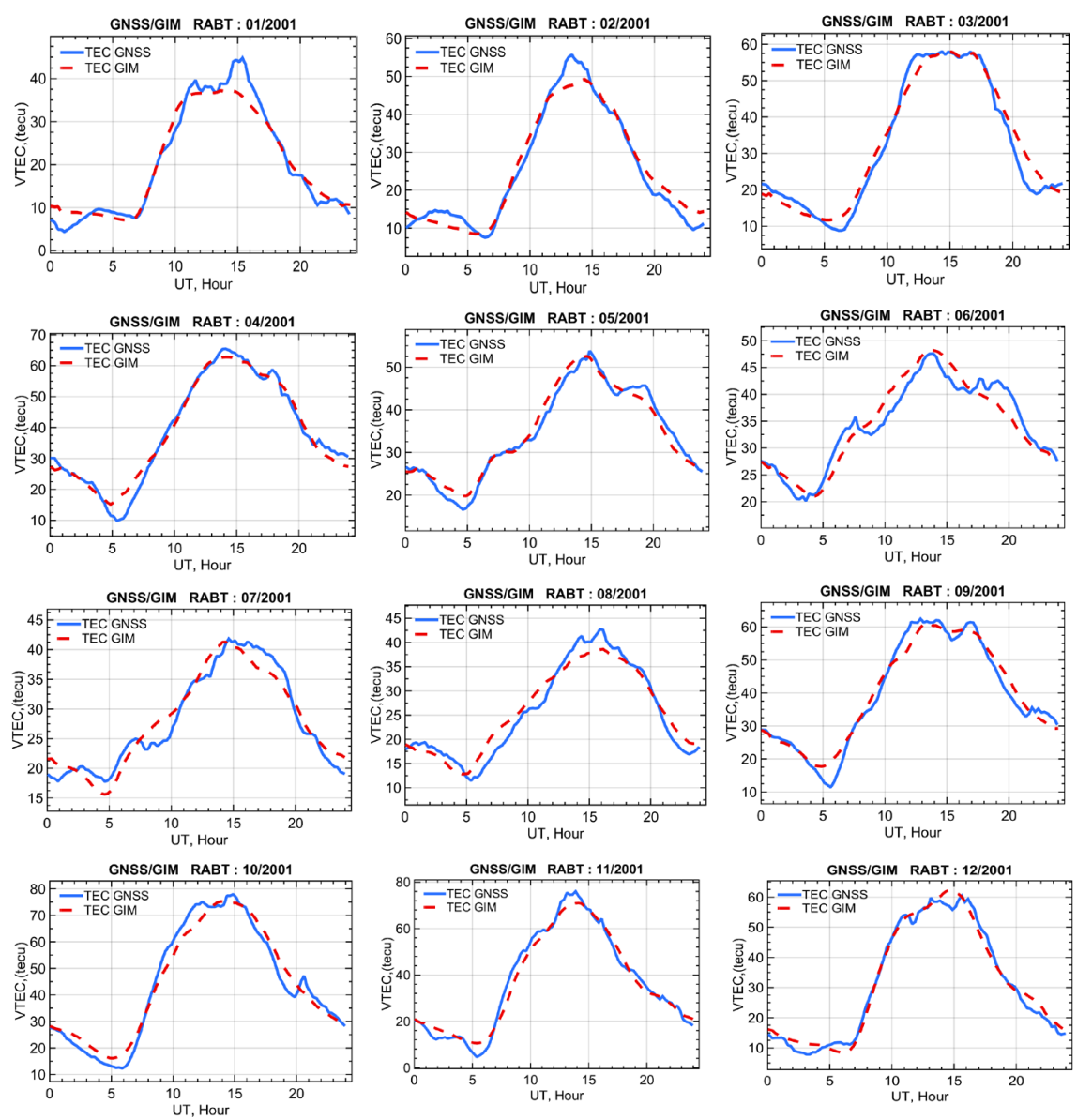

Figure 6. The monthly medians of the VTEC for the RABT station, during the year 2001 located at the maximum of solar cycle 3 . Cycle with strong activity. 

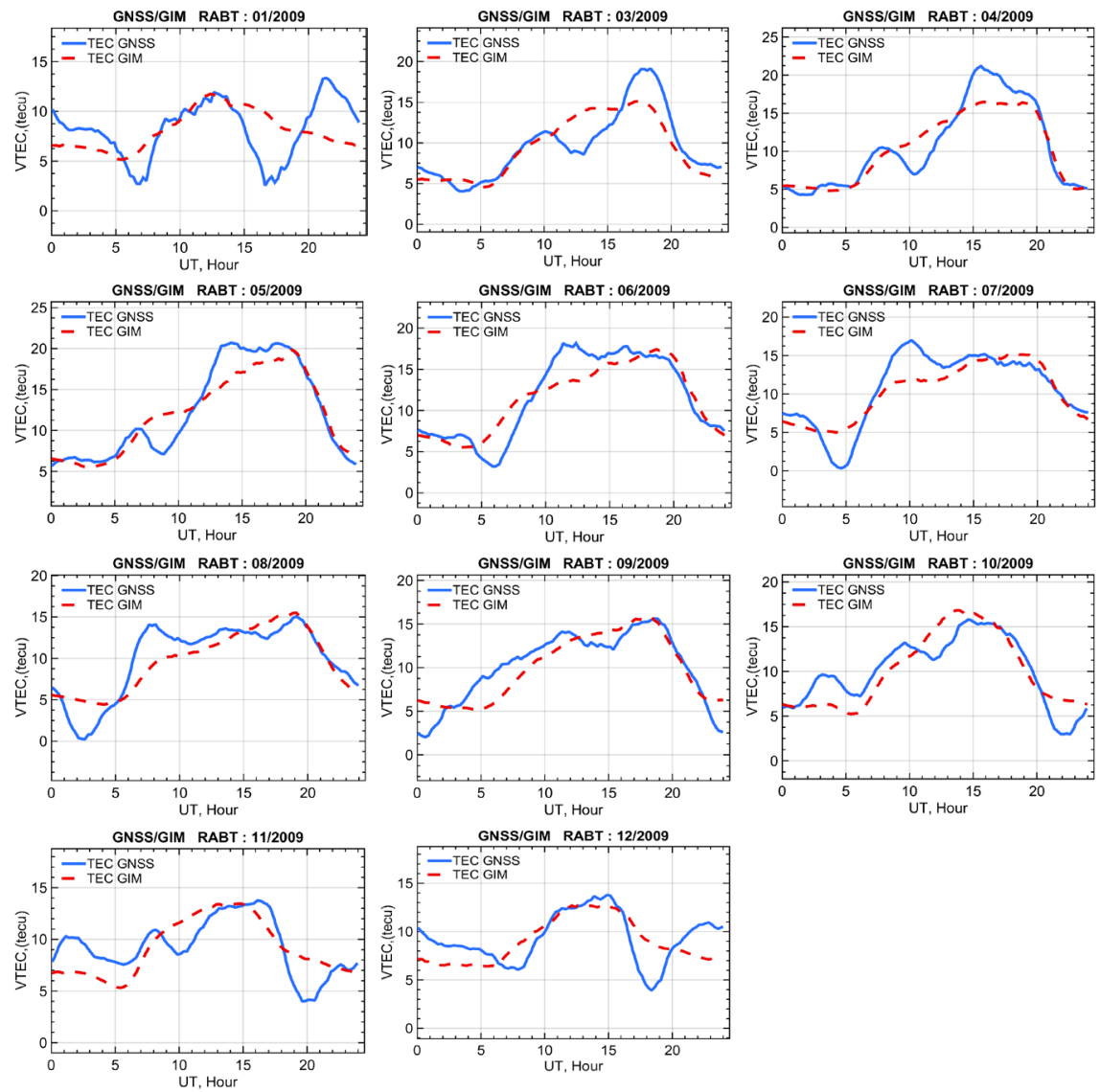

Figure 7. The monthly medians of the VTEC for the RABT station, during the year 2009 located at least of the solar cycle 23. with the exception of February due to instrument failure.

During the two years 2001 and 2013, the solar power is strong and the TEC is gradually hanging over the time interval 08 and 12 UT and decrease between 16 UT and 24 UT, just before the sunset. The peak values are found in the range of 15 - 25 TECU for all the month and seasons in the tree year, between the period of 12 UT and 16 UT. In addition, the peak value of the TEC was much longer in this period than in others. The value of VTEC overnight (20 TU and $04 \mathrm{TU}$ ), remains very low compared to the mid-day. The Inflexion Point of the value of TEC was detected during the whole year (2001-2009-2013) between 4 UT and 8 UT. The values of the TEC between 12 UT and 16UT are very different during the tree years of measurement. The sunspot number is over 150 during the year of 2001 rather than 2013 the sunspot number are between 85 and 115, so lower than in 2001. The results obtained from the RABT a TETN station show that the monthly variations of VTECare affected by the solar radiations.

The results of the TETN station are similar to those of the RABT station during the three years. The geographical position of the TEN stations justifies this result. In 2001, the VTEC measurements are large and not amplified at the spring equinox compared with the RABT station. In 2009 and 2013, the difference between the two curves VTEC-GNSS and VTEC-GIM is very minimal 1 to 

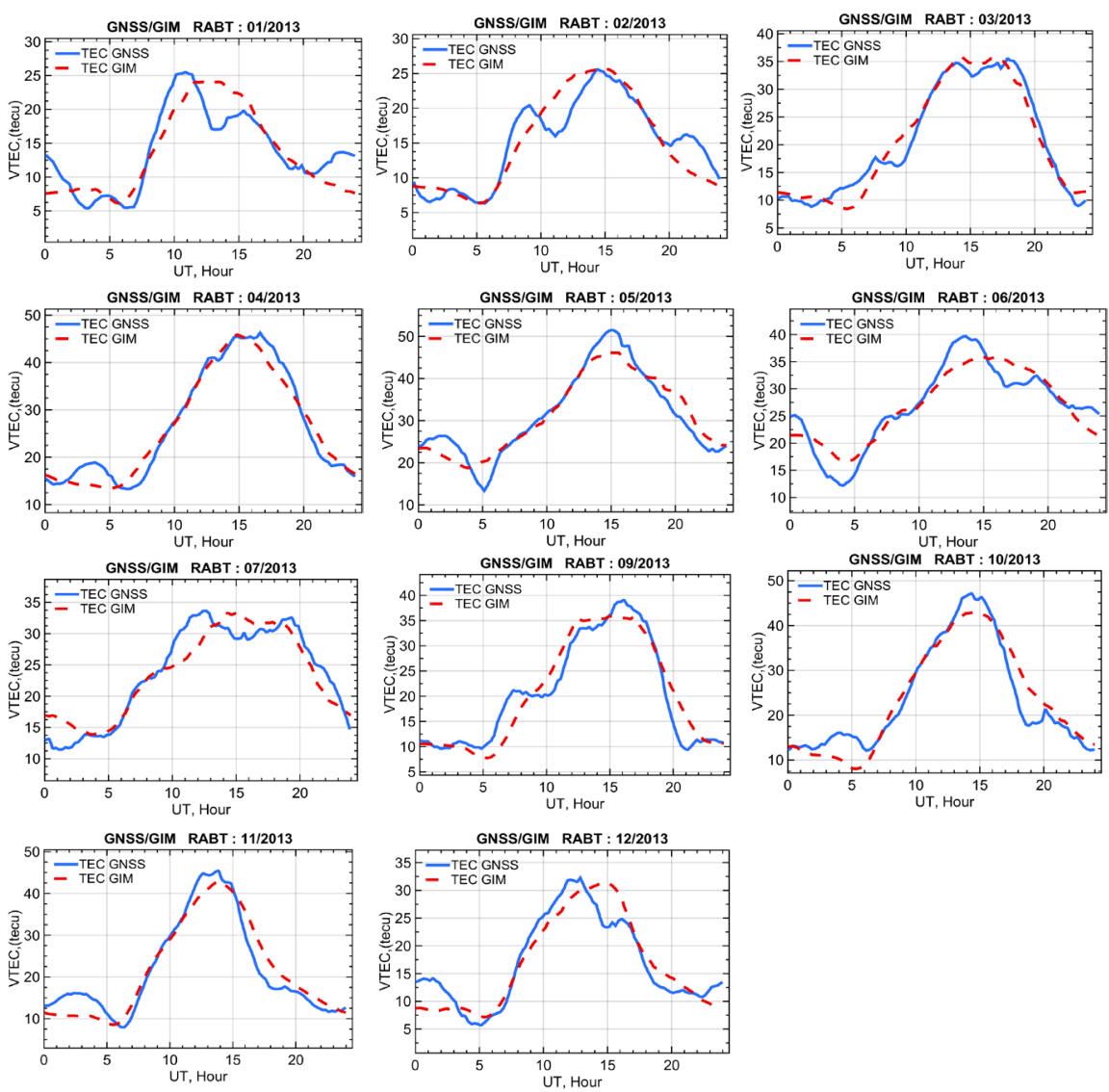

Figure 8. The monthly VTEC medians for the RABT station, during the year 2013 located at the maximum of the solar cycle 24 . Cycle of low activity.
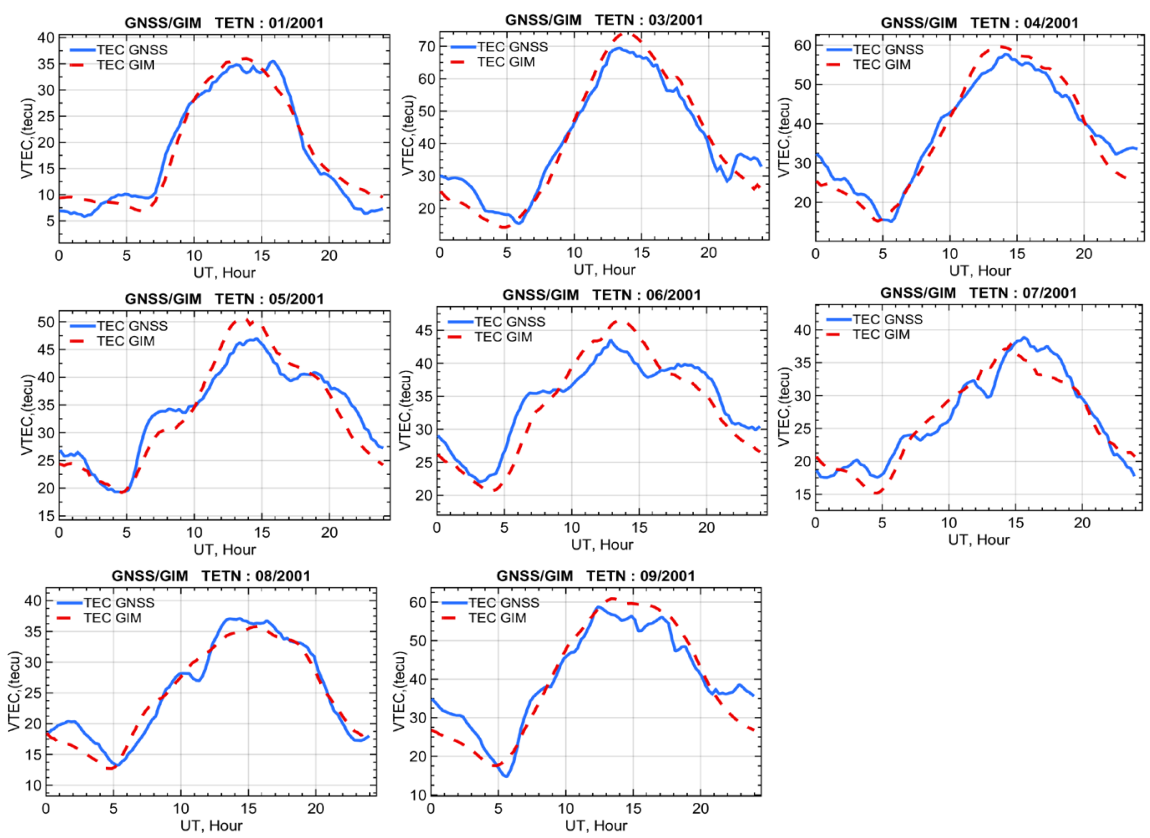

Figure 9. The monthly medians of Total Electron Content at TETN station during the year 2001 with the exception of February 2001 and October to December 2001 due to instrument failure. 

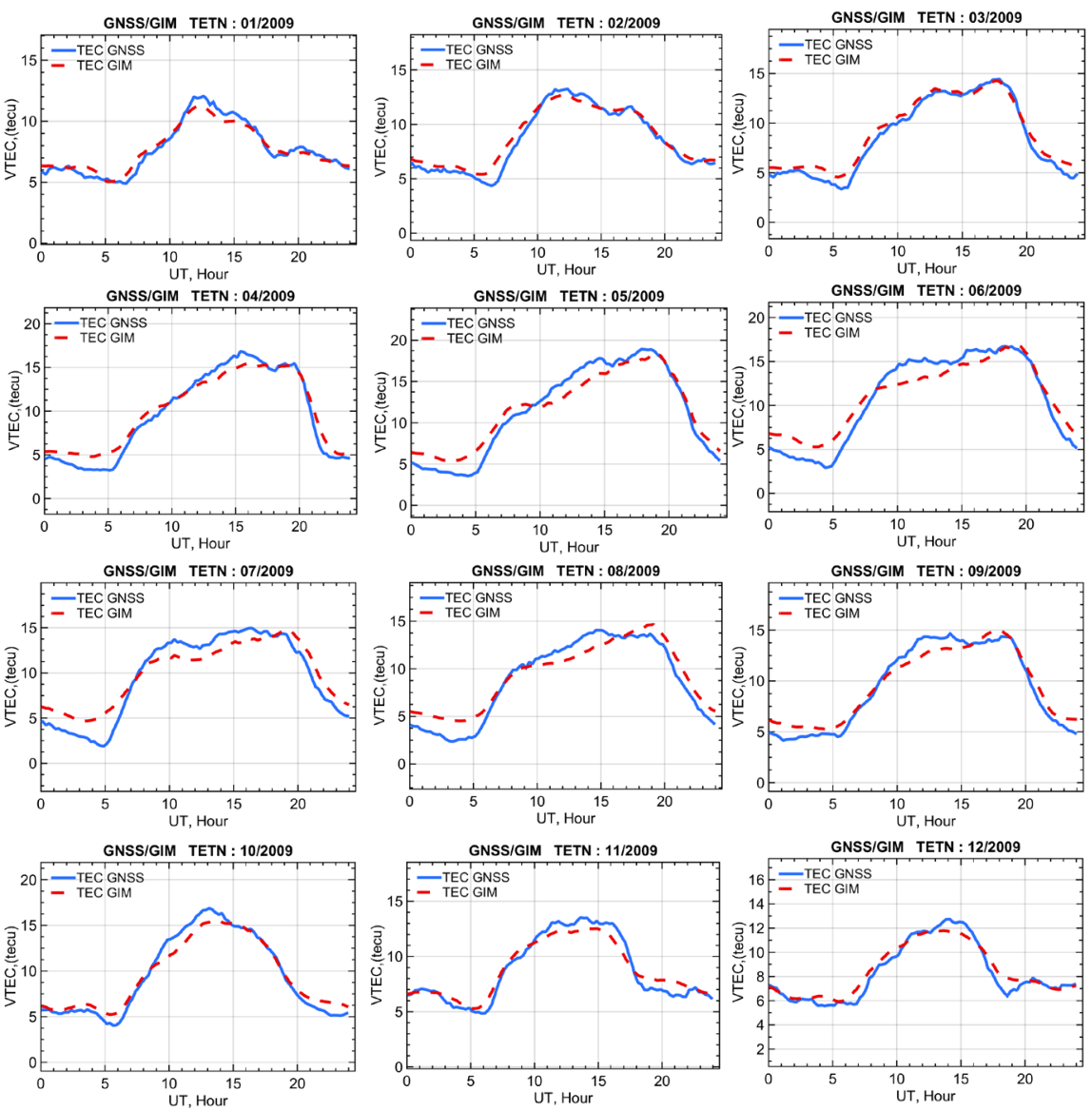

Figure 10. The monthly medians of Total Electron Content at TETN station during the year 2009.

2 tecu. What is not the case for the RABT station which has discrepancies going from 0 to 8 tecu. This is due to the RABT station which is closer to the south and therefore the VTEC values are stronger.

The maximum values of VTEC-GIM and VTEC-GNSS for two stations were observed at spring equinox (March and April) and winter equinox (October and November). Figure 12 shows the monthly average VTEC values obtained by different models at the RABT and TETN stations in 2001, 2009 and 2013. The values are calculated on average with all the TEC data collected during each month. In the three years, the monthly average TEC time series showed two peaks. In April-May and in September-October, The values of the TEC observed are greater at equinoxes, spring and winter, especially in the year of maximum solar 2001-2013. In 2009 solar minimum values of the TEC becomes more important at the summer solstice (June). The minimum values of the TEC observed during the three years are those attributed to the month of January.

\subsection{Seasonal Variation}

In order to validate our results, the correlation coefficients are calculated between the data VTEC-GNSS and VTEC-GIM for the year 2001 and 2009. For 

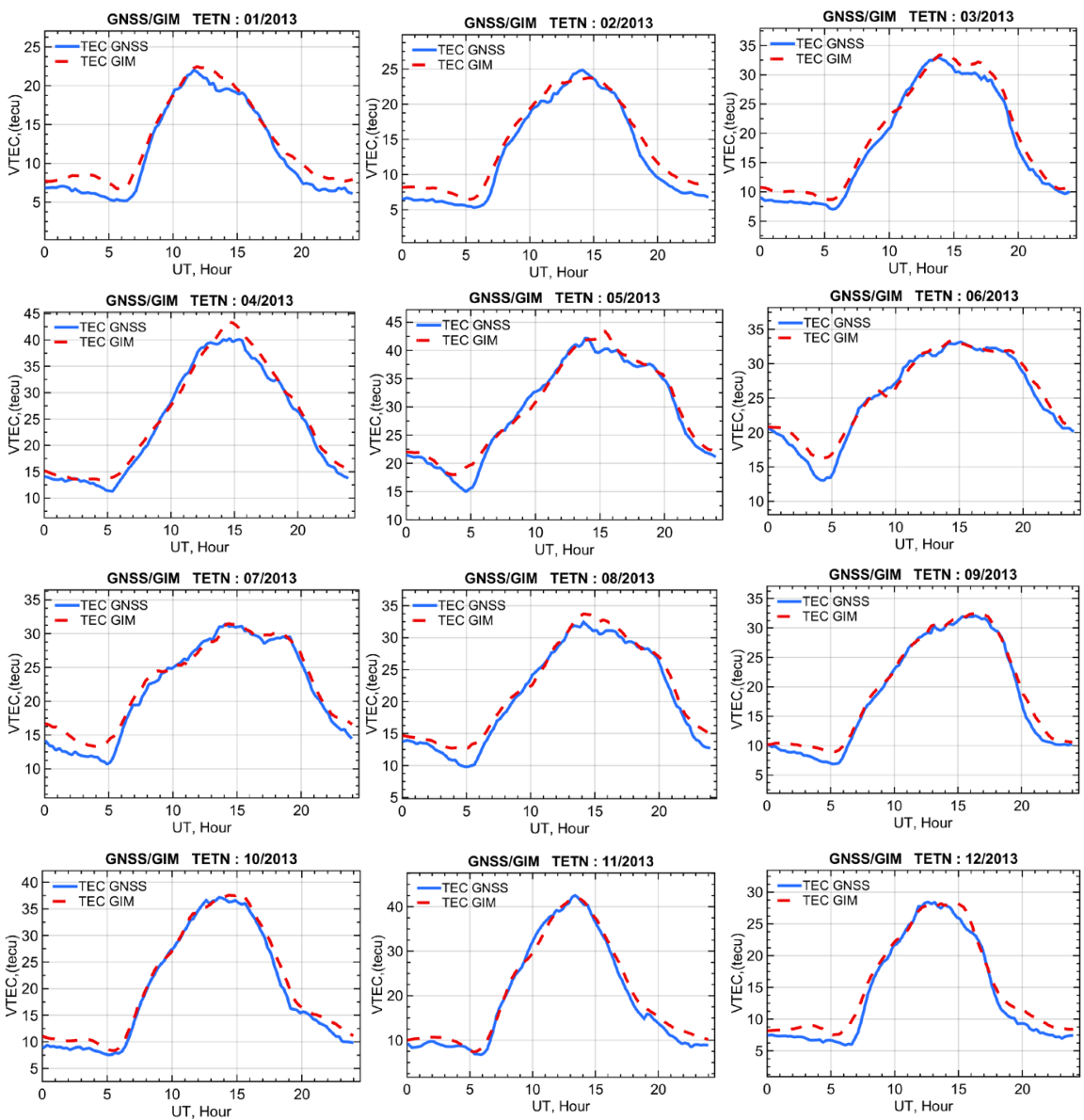

Figure 11. The monthly medians of Total Electron Content at TETN station during the year 2013.

comparison purposes we have started to choose three seasons to examine the variation of the TEC and the intensity of connection between the two models, the equinox (March, April, September and October), winter (November, December, January and February) and summer (May, June, July and August).

The correlation technique is used to mount if there is a strong connection between the models and if this connection is strong. The results of the correlation of the RABT station are shown in Figure 13 and Figure 14 and for TETN station are shown in Figure 15 and Figure 16. The results showed that the correlation coefficient between the two models for the two stations during the two years 2001 and 2009 is very important $(\approx 0.99)$, except for winter where it is 0.78 for the RABT station during the period 2009 Figure 14. This allows interpreting two things:

- As long as the coefficient is very positive, the VTEC-GNSS increases while the VTEC-GIM increases.

- the high intensity allows validating the reliability of the GIM model.

The GIM model is an ionospheric model based on more than 200 permanents stations. It is a model based on global statistics. The calculation of the TEC for mono station or regional method can be significant in terms of diurnal 

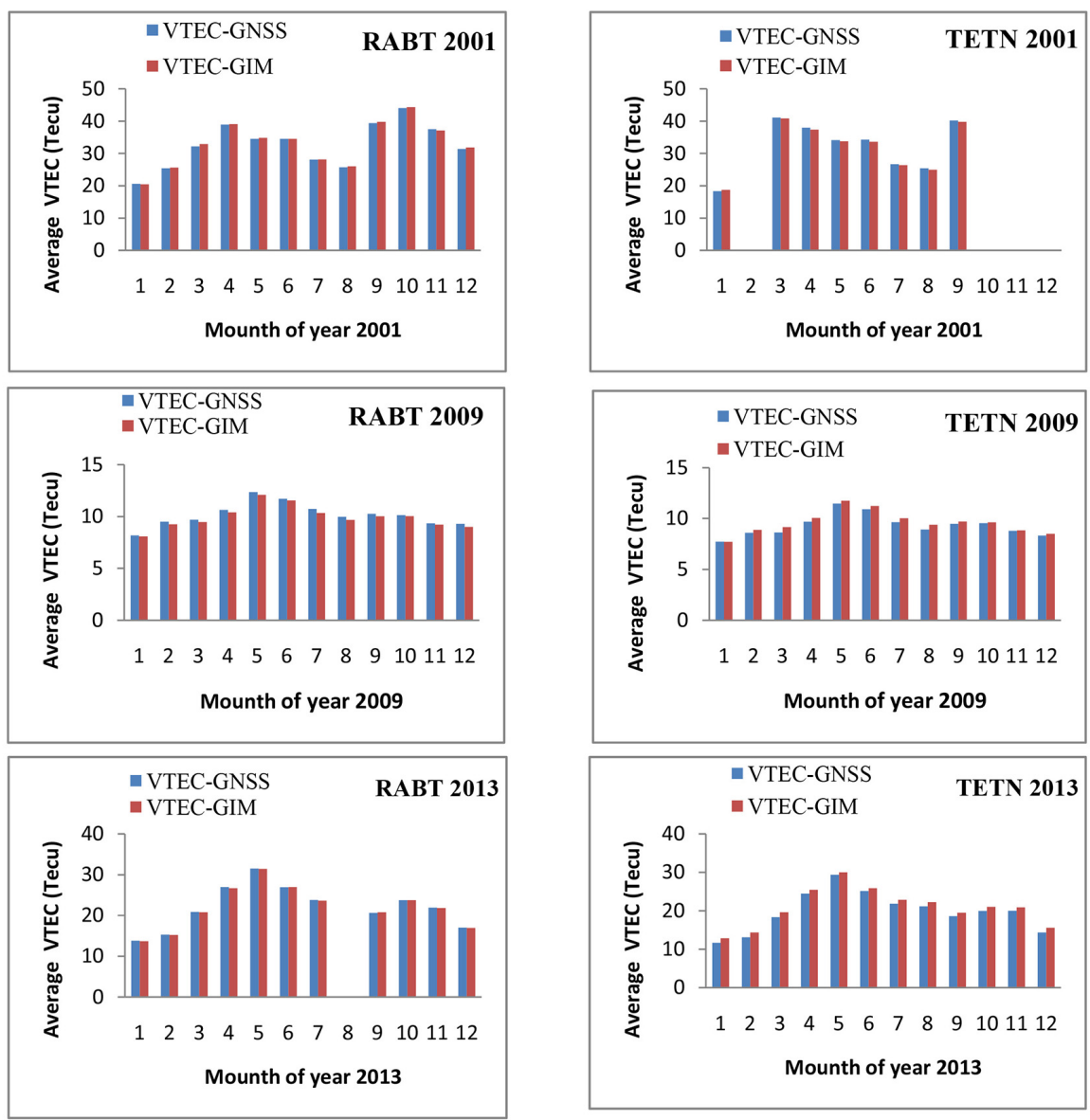

Figure 12. Monthly average values of VTEC for RABT and TETN stations in 2001, 2009 and 2013.
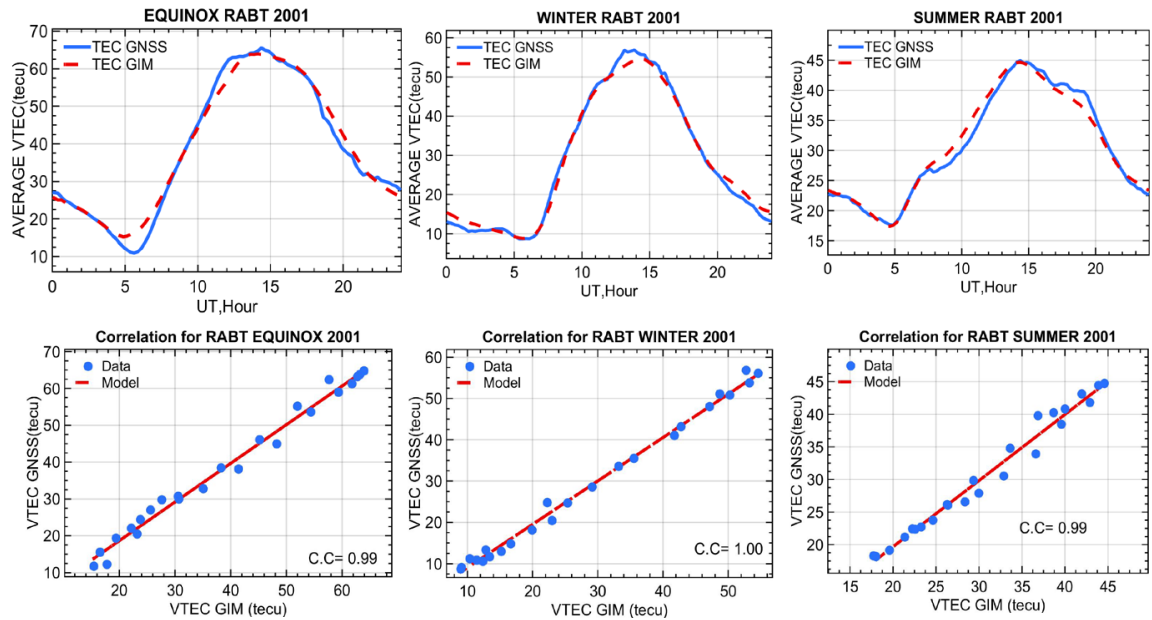

Figure 13. Correlation between the two models VTEC_GNSS and VTEC_GIM of the RABT station for the year 2001.

variations of the ionosphere. The sampling rate of RINEX observation in 30 seconds, allow giving more precision in the calculation of the VTEC, which is not the case of GIM model which provides values of the VTEC every 2 hours. 

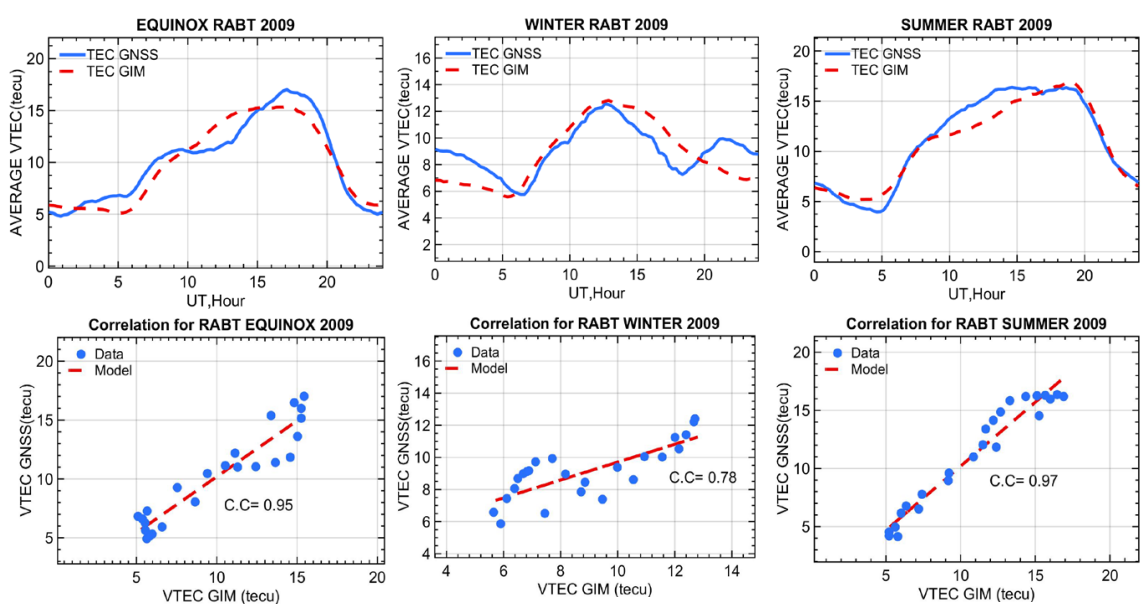

Figure 14. Correlation between the two models VTEC_GNSS and VTEC_GIM of the RABT station for the year 2009.
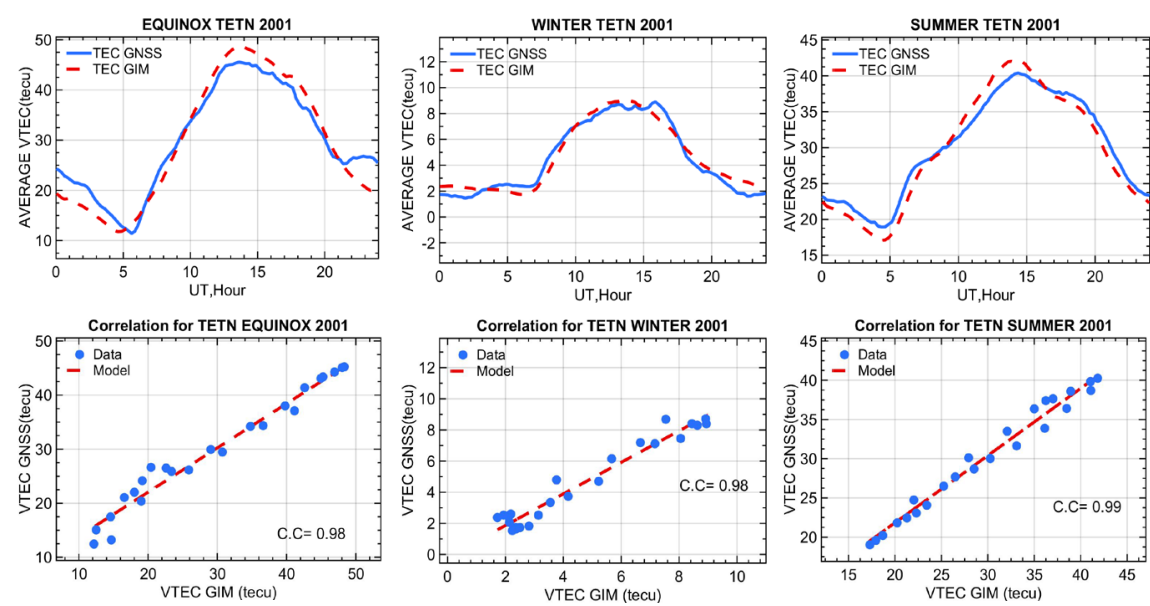

Figure 15. Correlation between the two models VTEC_GNSS and VTEC_GIM of the station TETN for the year 2001.
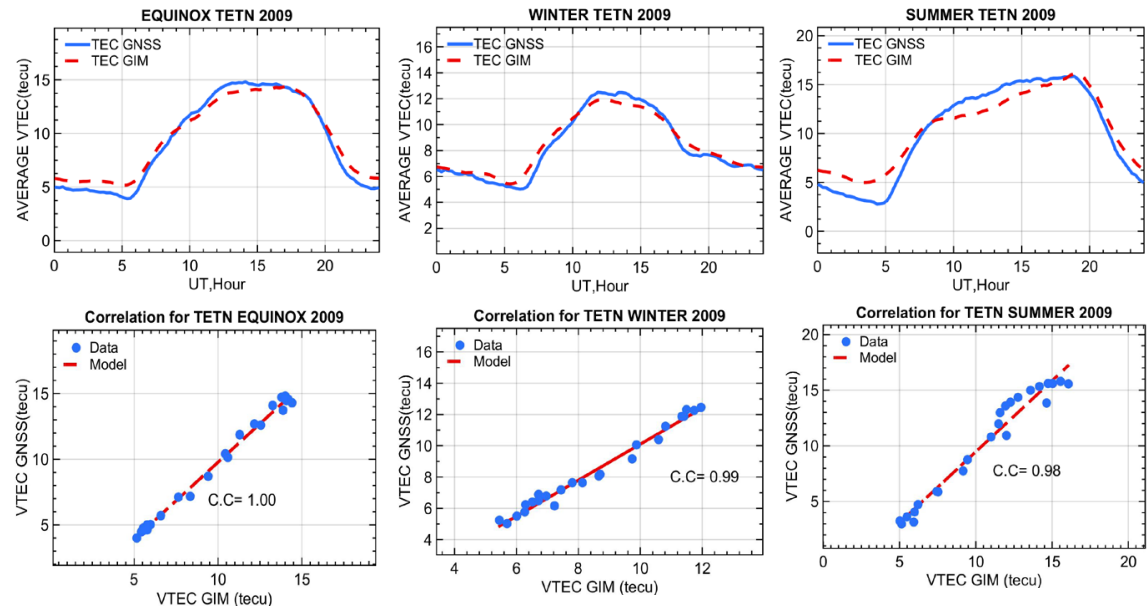

Figure 16. Correlation between the two models VTEC_GNSS and VTEC_GIM of the station TETN for the year 2009. 
AP2001--TECGNSS--TECGIM

RABT Station

डิ lat: $33^{\circ} 59^{\prime} 53.16^{\prime \prime} \mathrm{N}$ long : $6^{\circ} 51^{\prime} 15.12$ " W

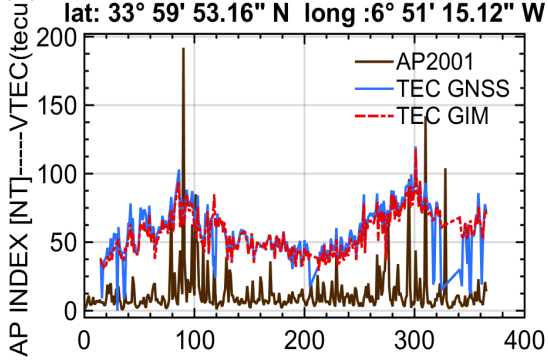

AP2009--TECGNSS--TECGIM RABT Station

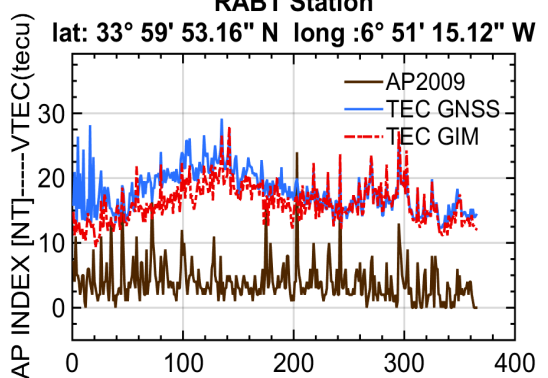

AP2001--TECGNSS--TECGIM

TETN Station

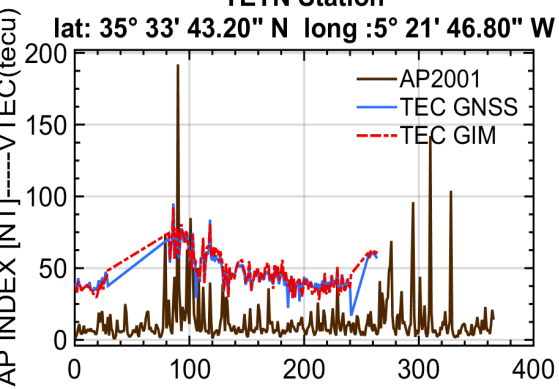

AP2009--TECGNSS--TECGIM TETN Station

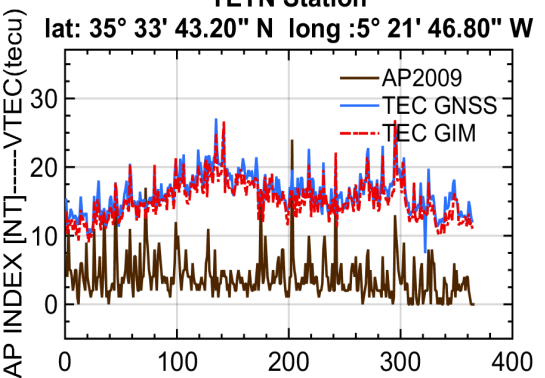

Figure 17. VTEC-GNSS, VTEC-GIM and AP index for the RABT and TETN station for the two years 2001 and 2009.

Table 2. WGS84 coordinates of reference stations.

\begin{tabular}{cccccc}
\hline STATION & COUNTRY & CITY & LATITUDE $\left(^{\circ}\right)$ & LONGITUDE $\left(^{\circ}\right)$ & HEIGHT (M) \\
\hline \multirow{2}{*}{ RABT } & Maroc & Rabat & 33.9981 & -6.8542 & 90.10 \\
\multirow{2}{*}{ TETN } & Maroc & Tetouan & 35.562 & -5.3630 & 63.714 \\
\hline
\end{tabular}

Table 3. Effect of geomagnetic activity on ionospheric error.

\begin{tabular}{cccccc}
\hline STATION & DOY & YEAR & AP & VTEC (tecu) & IONO DELAY L1 (m) \\
\hline $90-2001$ & 2001 & 192 & 66.48 & 10.79 \\
\multirow{2}{*}{ RABT } & $310-2001$ & 2001 & 142 & 93.43 & 15.17 \\
& $270-2001$ & 2001 & 104 & No data & No data \\
& $257-2009$ & 2009 & 0 & 15.47 & 3.65 \\
& $93-2009$ & 2009 & 1 & 19.37 & 2.51 \\
& $90-2001$ & 2001 & 192 & 59.35 & 3.14 \\
& $310-2001$ & 2001 & 142 & No data & No data \\
& $328-2001$ & 2001 & 104 & No data & No data \\
& $270-2009$ & 2009 & 2 & 21.84 & 3.54 \\
& $257-2009$ & 2009 & 0 & 14.35 & 2.33 \\
& $93-2009$ & 2009 & 1 & 16.88 & 2.74 \\
\hline
\end{tabular}




\subsection{Geomagnetic Activity}

From Figure 17, the calculation of VTEC is done for all days of the year. We opted to put a scale of comparison with the variation of the magnetic index to identify magnetic storms (Table 2). We took the average value of the VTEC for each day and plotted the result for the whole year.

A large variation in the maximum values of the parameters of the geomagnetic activity is observed between the two periods 2001 and 2009. According to our results presented in Figure 17, the values of the VTEC confirm the same variation. This leads to the conclusion that the geomagnetic activity affects the TEC data largely during the period of high activity (2001) compared to the period of low activity (2009). Table 3 presents the result of calculation of the ionospheric error on the L1 band of the two GNSS stations during the two solar years 2001 and 2009.

\section{Conclusions}

In this study, we calculated the ionospheric TEC at the RABT and TETN station in year with high solar activity (2001) and year with low solar activity (2009). Then, we analyzed the diurnal variation, monthly variation, and solar dependence of the TEC. The main results are as follows:

- TEC value generally increased in the period of 07:00 to 10:00 UT inall seasons and was maximized in the period of 12:00 to 16:00 $\mathrm{h}$ UT.

- The maximum values of TEC were found during the equinox and winter for both measurement years 2001 and 2009. In the first period of 2001 the maximum values for RABT and TETN station $\approx 40-50$ TECU, during the equinox and the minimum was found in the winter $\approx 12-17$ TECU.

- The comparison between VTEC-GNSS and VTEC-GIM allowed us to validate our methology for computing ionospheric VTEC. A strong correlation $(\approx 0.99)$ between the VTEC-GNSS and VTEC-GIM has been found for all season except winter season $(\approx 0.78)$ for RABT station in period 2009 . Therefore, it maybe concluded that the TEC value will be maximum during equinox season which may be attributed to solar activity for each period.

- The effect of geomagnetic storm on the ionosphere provides a positioning error ranging from $2.33 \mathrm{~m}$ to $15.17 \mathrm{~m}$ in period of low and high solar activity

\section{Acknowledgements}

I am grateful to Dr. Bouziani Mouradand Dr. Christine Amory-Mazaudiez for given me the study leave in Telecom Bretagne Institute to process ionosphere GPS data. I am immensely grateful to Dr. Rolland Fleury for his technical training at matlab programming level. Authors thanks the International GNSS Service (IGS) and the Center for Orbit Determination in Europe, University of Berne (CODE) who made the RINEX files and IONEX files available.

\section{Conflicts of Interest}

The authors declare no conflicts of interest regarding the publication of this paper. 


\section{References}

[1] Warnant, R. (2006) l'effet de l'atmosphère terrestre sur les GNSS: Une perturbation ou un signal géophysique? Bulletin de la Société géographique de Liège, 47, 19-23.

[2] International GNSS Service. ftp://cddis.gsfc.nasa.gov/gnss/products/

[3] Smith, C.A. (1987) Ionospheric TEC Estimation with a Single-Frequency GPS Receiver. The Effect of the Ionosphere on Communication, Navigation and Surveillance Systems. Ionospheric Effects Symposium. Naval Research Laboratory.

[4] Warnant, R. (1996) Etude du comportement du contenu électronique total et de sesirrégularités dans une région de latitude moyenne. Application aux calculs depositions relatives par le GPS. Observatoire Royal de Belgique.

[5] Jin, R., Jin, S. and Feng, G. (2012) M_DCB: Matlab Code for Estimating GNSS Satellite and Receiver Differential Code Biases. GPS Solutions, 16, 541-548. https://doi.org/10.1007/s10291-012-0279-3

[6] Shukla, A.K., Neha, N., Saurabh, D., Nishkam, J., Sivaraman, M.R. and Bandyopadhyay, K. (2008) Statistical Comparison of Various Interpolation Algorithms for Grid Based Single Shell Ionospheric Model over Indian Region. Journal of Global Positioning Systems, 7, 72-79. https://doi.org/10.5081/jgps.7.1.72

[7] Gao, Y. and Liu, Z.Z. (2002) Precise Ionosphere Modelling Using Regional GPS Network Data. Journal of Global Positioning Systems, 1, 18-24. https://doi.org/10.5081/jgps.1.1.18

[8] Schaer, S. (1999) Mapping and Predicting the Earth's Ionosphere Using the Global Positioning System. Thesis, University of Berne, Berne, 228 p.

[9] Seeber, G. (2003) Satellite Geodesy. 2nd Edition, Walter de Gruyter, Berlin, 589 p. https://doi.org/10.1515/9783110200089

[10] Liu, J., Chen, R., Wang, Z. and Zhang, H. (2011) Spherical Cap Harmonic Model for Mapping and Predicting Regional TEC. GPS Solutions, 15, 109-119. https://doi.org/10.1007/s10291-010-0174-8

[11] Davies, K. (1990) Ionospheric Radio. IEEE Electromagnetic Waves Series 31, Peter Peregrinus, London.

[12] Schaer, S., Gurtner, W. and Feltens, J (1998) IONEX: The IONosphere map Exchange Format Version 1. Proceedings of the IGS AC Workshop, Darmstadt, 9-11 February 1998, 233-247. 